\title{
Influence of Hazy Weather on Patient Presentation with Respiratory Diseases in Beijing, China
}

\author{
Jie Ping
}

\begin{abstract}
Background: Chronic respiratory disease is an important factor for development of lung cancer. To explore the influence of hazy weather on respiratory diseases and its variation the present study was conducted. Materials and Methods: Data from air pollution surveillance from January to October 2014 and case records of visiting patients in the $23^{\text {th }}$ Hospital of Chinese PLA in the corresponding period were collected to analyze the relevance between different degrees of air pollution (hazy weather) and the number of visiting patients in Department of Respiratory Disease. Results: Air quality index (AQI) of hazy weather had significantly positive association with particulate matter $2.5\left(\mathrm{PM}_{2.5}\right)$ and the number of patients with 5 kinds of respiratory diseases $i$ and different pollutants had distinct influences on various respiratory diseases. Conclusions: The degree of air pollution in Beijing City is in close association with the number of patients with respiratory diseases, in which $\mathbf{P M}_{2.5}$ and $\mathrm{SO}_{2}$ are in more significant influences on all respiratory diseases. This could have essential implications for lung cancer development in China.
\end{abstract}

Keywords: Hazy weather - air quality index - respiratory diseases - $\mathrm{PM}_{2.5}-\mathrm{SO}_{2}$ - relevance

Asian Pac J Cancer Prev, 16 (2), 607-611

\section{Introduction}

The latest edition of Global Burden of Disease (GBD) published by World Health Organization (WHO) in 2010 restates that air pollution is one of the principal risk factors impacting human health (Lim et al., 2012). In addition to directly cauisng respiratory problems, the resultant chronic bronchitis and emphysema are positively associated with lung cancer demelopment (Katanoda et al., 2011; Denholm et al., 2014).

In recent years, with the rapid development of Chinese economic level, air pollution problems have become increasingly sharp. In domestic, hazy weather occurs frequently in multiple provinces, especially the large-scale one in winter of Northern area in 2013, which may lead to serious healthy damages, thus receiving increasingly more social attentions. In January 2014, a large-scale hazy weather lasted for days and covered 17 provinces, cities and regions, affecting about 6 billion populations. According to the surveillance data from Ministry of Environmental Protection, during the first half year of 2014 , the ratio of total days with excessive-standard air quality was $39.7 \%$ in 74 cities and that with severe and serious pollution was $7.5 \%$. The primary pollutants inducing hazy weather include particulate matter 2.5 $\left(\mathrm{PM}_{2.5}\right)$, inhalable particulate matter 10 (PM10), sulfur dioxide $\left(\mathrm{SO}_{2}\right)$, nitrogen dioxide $\left(\mathrm{NO}_{2}\right)$, nitric oxide $(\mathrm{CO})$ and ozone $\left(\mathrm{O}_{3}\right)$.
To explore the influence of different-degree air pollution (hazy weather) and different pollutants on respiratory diseases, the surveillance data of air pollution obtained from January to October 2014 and case records of visiting patients in the $263^{\text {th }}$ Hospital of Chinese PLA in corresponding period were systematically collected, hoping to provide theoretical basis for the prevention, diagnosis and treatment of respiratory diseases in similar air quality and weather condition.

\section{Materials and Methods}

\section{General data}

Surveillance data of air pollution: The data, which were obtained from China National Environmental Monitor Center, were consisted of air target days and the quality concentration of 6 pollutants in air quality index (AQI) of GB 3095-2012 Ambient Air Quality Standard (AAQS), including $\mathrm{PM}_{2.5}, \mathrm{PM}_{10}, \mathrm{SO}_{2}, \mathrm{NO}_{2}, \mathrm{CO}$ and $\mathrm{O}_{3}$.

Data of outpatients: The data, which were taken from the Department of Respiratory in the $263^{\text {th }}$ Hospital of Chinese PLA, were collected from patients with respiratory diseases such as chronic obstructive pulmonary disease (COPD), upper respiratory tract infection, pneumonia and asthma, etc. Patients with $\geq 2$ above descriptions in inclusion criteria were classified by their primary diagnosis so as to avoid repeated statistical analysis. 


\section{Methods}

Surveillance data of air pollution obtained from January $1^{\text {th }}$ to October $31^{\text {th }} 2014$ and case records of patients diagnosed with respiratory diseases who were treated in the $263^{\text {th }}$ Hospital of Chinese PLA in corresponding period were collected. The monthly total number of visiting patients was recorded and the number of outpatients with each primary respiratory disease (such as bronchitis, bronchial asthma, upper respiratory tract infection, COPD and pneumonia) for initial diagnosis in Department of Respiratory was calculated. According to the air quality data published by local Department of Environmental Protection in the corresponding period, the monthly and percentile concentration values of 6 pollutants were calculated. Then, the AQI value was calculated by integrating the above data. Database including the data of hazy weather, number of visiting patients and the number of patients with each respiratory disease was established to analyze the relationship between AQI and the number of patients with 5 primary respiratory diseases, and the influencing degree of different pollutants on distinct respiratory diseases.

\section{Evaluation criteria}

AQI calculation, which referred to GB 3095-2012 Ambient Air Quality Standard, including the monthly average concentrations of $\mathrm{SO}_{2}, \mathrm{NO}_{2}, \mathrm{PM}_{10}$ and $\mathrm{PM}_{2.5}$, the $95^{\text {th }}$ percentile of daily $\mathrm{CO}$ average concentration and the $90^{\text {th }}$ percentile of daily $\mathrm{O}^{3}$ maximum 8 -h concentration. The higher the AQI, the severer the pollution condition of hazy weather.

\section{Statistical data analysis}

SPSS 18.0 statistical software was applied. The single index $\mathrm{Ii}(\mathrm{Ii}=\mathrm{Ci} / \mathrm{Si}, \mathrm{Ci}$ referred to the monthly average or percentile concentration value of each pollutant while $\mathrm{Si}$ as the secondary standard of annual average value of pollutant $i$ ) of each pollutant and the comprehensive AQI (AQI= $\sum$ Ii) of above 6 pollutants were calculated. Multiple linear regression analysis was conducted for the relevance between AQI value and the concentration of each pollutant, the total visiting patient number and the single number of patients with 5 respiratory diseases so as to calculate the correlation coefficient, with significant level $\alpha=0.05$.

\section{Results}

Meteorological data of hazy weather

During January 1 th to October $31^{\text {th }} 2014$, AQI value was the lowest in June with slight hazy weather because the monthly days with standard air quality were 15 , whereas it was the highest in February with severe hazy weather in that the monthly days with standard air quality were 9 (Table 1 ).

\section{Relevance analysis of AQI and each pollutant concentration parameter}

There was certain association between the 6 pollutant indexes and AQI values $(\alpha=0.01)$, in which PM10, CO, $\mathrm{SO}_{2}$ and $\mathrm{NO}_{2}$ were in positive association with $\mathrm{AQI}$, with correlation coefficients being $0.888,0.874,0.816$ and 0.814 , respectively. The correlation coefficient of PM2.5 $(r=0.975)$ was the highest and in positive connection, indicating that the higher the $\mathrm{PM}_{2.5}$, the severer the hazy weather pollution, whereas $\mathrm{O} 3$ was in negative relationship with AQI (r=-0.794). Figure 1 is showing the trend chart of each pollutant concentration parameter and AQI.

Relevance analysis of hazy weather and respiratory diseases

During observation period, the number of visiting patients increased gradually along with the increase

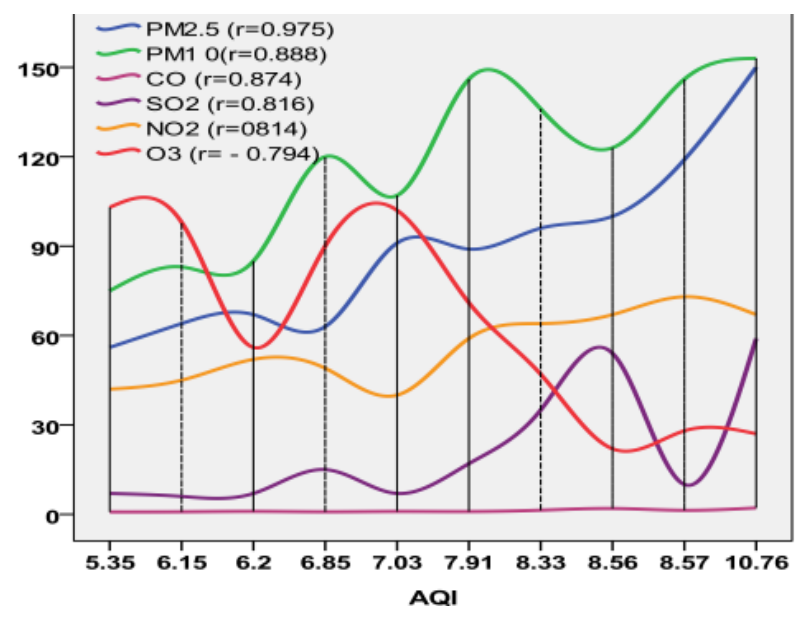

Figure 1. Trend Chart of Air Pollutant Concentrations and AQI Changes

Table 1. Surveillance Condition of Air Quality in Beijing from January to October, 2014

\begin{tabular}{|c|c|c|c|c|c|c|c|c|}
\hline Time & $\begin{array}{l}\mathrm{C}^{\mathrm{aPM}}{ }_{2.5} \\
\left(\mathrm{mg} / \mathrm{m}^{3}\right)\end{array}$ & $\begin{array}{l}\mathrm{C}^{\mathrm{aPM}}{ }_{10} \\
\left(\mathrm{mg} / \mathrm{m}^{3}\right)\end{array}$ & $\begin{array}{l}\mathrm{C}^{\mathrm{aSO}}{ }_{2} \\
\left(\mathrm{mg} / \mathrm{m}^{3}\right)\end{array}$ & $\begin{array}{l}\mathrm{C}^{\mathrm{a} N O}{ }_{2} \\
\left(\mathrm{mg} / \mathrm{m}^{3}\right)\end{array}$ & $\begin{array}{c}\mathrm{C}^{\mathrm{a}} \mathrm{O}_{3} \\
\left(\mu \mathrm{g} / \mathrm{m}^{3}\right)\end{array}$ & $\begin{array}{c}\mathrm{C}^{\mathrm{a}} \mathrm{CO} \\
\left(\mathrm{mg} / \mathrm{m}^{3}\right)\end{array}$ & $\mathrm{AQI}^{\mathrm{b}}$ & $\begin{array}{c}\text { Standard days/ } \\
\text { monthsc }\end{array}$ \\
\hline 2014-1 & 100 & 123 & 54 & 67 & 22 & 1.96 & 8.56 & 12 \\
\hline 2014-2 & 150 & 153 & 59 & 67 & 27 & 2.15 & 10.76 & 9 \\
\hline 2014-3 & 96 & 136 & 35 & 64 & 47 & 1.38 & 8.33 & 15 \\
\hline 2014-4 & 89 & 146 & 17 & 59 & 71 & 0.92 & 7.91 & 13 \\
\hline $2014-5$ & 63 & 120 & 15 & 49 & 90 & 0.84 & 6.85 & 15 \\
\hline 2014-6 & 56 & 75 & 7 & 42 & 103 & 0.8 & 5.35 & 15 \\
\hline 2014-7 & 91 & 107 & 7 & 40 & 102 & 0.96 & 7.03 & 9 \\
\hline 2014-8 & 64 & 83 & 6 & 45 & 98 & 0.84 & 6.14 & 10 \\
\hline 2014-9 & 67 & 85 & 7 & 52 & 56 & 0.98 & 6.2 & 14 \\
\hline 2014-10 & 119 & 146 & 10 & 73 & 28 & 1.34 & 8.57 & 15 \\
\hline
\end{tabular}

a: $\mathrm{SO}_{2}, \mathrm{NO}_{2}, \mathrm{PM}_{10}$ and $\mathrm{PM}_{2.5}$ concentrations were defined as the monthly average ones, $\mathrm{CO}$ concentration as the $95^{\text {th }}$ percentile of daily average concentration and $\mathrm{O}_{3}$ concentration as the $90^{\text {th }}$ percentile of the daily maximum 8 -h concentration; ${ }^{\text {b }}$ : It referred to the AQI value calculated by the monthly average value of each index or the percentile concentration; C: The index of days with standard air quality referred to GB 3095-2012 Ambient Air Quality Standard 
Table 2. Correlation Coefficients of Atmospheric Pollutants and the Number of Patients with Respiratory Diseases

\begin{tabular}{|c|c|c|c|c|c|c|}
\hline Types & Bronchitis & $\begin{array}{l}\text { Bronchial } \\
\text { asthma }\end{array}$ & $\begin{array}{c}\text { Upper respiratory } \\
\text { infection }\end{array}$ & COPD & Pneumonia & $\begin{array}{c}\text { Total cases of } \\
\text { patients }\end{array}$ \\
\hline $\mathrm{PM}_{2.5}$ & $0.865 * *$ & $0.872 * *$ & $0.942 *$ & $0.935 * *$ & $0.895 * *$ & $0.952 * *$ \\
\hline $\mathrm{PM}_{10}^{2.3}$ & 0.446 & $0.845^{* *}$ & $0.812 * *$ & $0.879 * *$ & $0.810 * *$ & $0.870 * *$ \\
\hline $\mathrm{SO}_{2}$ & $0.697 *$ & $0.921 * *$ & $0.804 * *$ & $0.728 * *$ & $0.795 * *$ & $0.792 *$ \\
\hline $\mathrm{NO}_{2}$ & 0.456 & $0.958 * *$ & $0.735^{*}$ & 0.611 & $0.825 * *$ & $0.874 * *$ \\
\hline $\mathrm{O}_{3}$ & -0.562 & 0.455 & 0.598 & $-0.747 *-0.776$ & $-0.858 * *$ & \\
\hline $\mathrm{CO}$ & 0.613 & $0.754 *$ & $0.772 * *$ & $0.744^{*}$ & $0.660 *$ & $0.816 * *$ \\
\hline AQI & $0.748 *$ & $0.879 * *$ & $0.856 * *$ & $0.917 * *$ & $0.830 * *$ & $0.946 * *$ \\
\hline
\end{tabular}

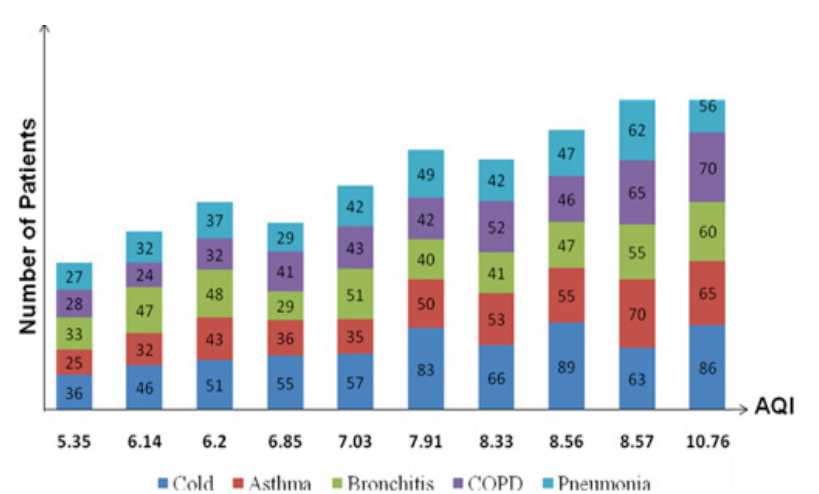

Figure 2. Trend Chart of AQI and Number of Patients with Respiratory diseases

of AQI value. AQI value was the highest in February $(\mathrm{AQI}=10.76)$ and the lowest in June (AQI=5.35), during which time the numbers of patients with 5 respiratory diseases in Department of Respiratory Disease were up to 337 and only 149 , respectively. Figure 2 is showing the relationship between AQI value and the total number of visiting patients due to respiratory diseases and number of patients with primary respiratory diseases.

There was significant relevance between the 6 air pollutants and the total number of visiting patients and the number of patients with principal respiratory diseases, in which $\mathrm{PM}_{2.5}$ and $\mathrm{SO}_{2}$ had the closest association with each disease, whereas $\mathrm{PM}_{10}$ and $\mathrm{CO}$ were positively related with bronchial asthma, upper respiratory tract infection, COPD and pneumonia $(p<0.01)$, but had no connection with bronchitis. However, $\mathrm{O}_{3}$ was in negative correlation with COPD and pneumonia (Table 2).

\section{Discussion}

Difference analysis of $\mathrm{PM}_{25}$ concentrations on the number of visiting patients in Department of Respiratory

$\mathrm{PM}_{25}$ is defined as the particulate matter (PM) with diameter $\leq 2.5 \mu \mathrm{m}$ in air. It was found that the shorter the diameter of PM, the larger the corresponding amount concentration and the total area, which would absorb more harmful substances into human body and bring about more harms to human health (Meng et al., 2013). $\mathrm{PM}_{2.5}$, as is marked by tiny diameter, strong toxicity, longer retaining duration, remote transportation distance and no filtering resistance due to the physical construction, can enter into human body along with respiration and go deep into pulmonary alveolus for deposition, which then can disturb the gas exchange and blood circulation, thus leading to respiratory diseases.
About $90 \%$ of global populations are in long-term exposure of $\mathrm{PM}_{25}$ above the upper limit of World Health Organization (WHO) Air Quality Standard (Brauer et al., 2012), which issue is more sharp in Asian countries where the $\mathrm{PM}_{2.5}$ concentration is much more higher than many other countries and regions (McClellan et al., 2012). In East-Asian area, one of the most contaminative places across the world, $\mathrm{PM}_{25}$ is the fourth cause of early deaths (Brook et al., 2010). A survey in Taiwan showed that the daily number of COPD outpatients was in obvious association with $\mathrm{PM}_{2.5}$ concentration (Wang et al., 2013). In addition, another research indicated that the increase of $\mathrm{PM}_{2.5}$ concentration was closely correlated with the increase of patients with bronchitis (Guo et al., 2014). Annesi-Maesano (Annesi-Maesano et al., 2007) found that the morbidity of asthma and bronchitis induced by exercises was apparently connected with $\mathrm{PM}_{2.5}$ concentration, which was evidently higher in high-concentration region than that in low-concentration region. Present study on the relevance between $\mathrm{PM}_{2.5}$ concentration and adult asthma is rare, but there are some researches revealed that the closer the distance from $\mathrm{PM}_{2.5}$ pollution sources, the higher the morbidity of asthma and more serious the aggravated asthma symptoms (Oyana et al., 2005). Kantanoda performed a cohort study of 63520 patients from 6 continents and 6 regions of Japan and demonstrated that the increase of morbidity of respiratory diseases, especially pneumonia, was in significant association with the long-term exposure of air PM (Katanoda et al., 2011). This work also suggested that $\mathrm{PM}_{2.5}$ concentration was associated with the monthly number of visiting patients with bronchial asthma, bronchitis, upper respiratory tract disease, COPD and pneumonia, which was consistent with the research results at home and abroad.

With the growing development of recent studies, the mechanism of respiratory diseases induced by PM in environment can be summarized as follows: Theory of transcription factors and inflammation-associated cytokine activation: $\mathrm{PM}_{2.5}$ exposure may stimulate the increasing release of inflammatory factors in human body to trigger inflammatory damage. Studies revealed that $\mathrm{PM}_{2.5}$ exposure was in concentration- and time-dependent association with the inflammatory damage (Lippmann et al., 2005; Rouse et al., 2008). The present researches pointed out that $\mathrm{PM}_{2.5}$ could increase the release of inflammatory factors through following mechanisms: $i$ ) PM could up-regulate the production of inflammatory and pro-inflammatory factors after entering into human body, such as tumor necrosis factor- $\alpha$ (TNF- $\alpha$ ), interleukin-1 
(IL-1), IL-6 and L3 (Deng et al., 2013; Deng et al., 2013); ii) Phagocytes could consume oxygen in the process of swallowing PM, which could induce the release of inflammatory factors following by the production of free radicals in the outside of cells; iii) The inflammatory factors could directly lead to the inflammatory responses in local lung tissues, bringing about alveolar epithelial damage; i) Damaged and disintegrated phagocytes could release oxygen free radicals, protease and inflammatory factors and activate the inflammatory response, in which the acute inflammation in lung could further promote the release of inflammatory factors (Ruckerl et al., 2014). In short, $\mathrm{PM}_{25}$ exposure can induce excessive and enduring inflammatory responses and the over-release of inflammatory mediators, which can cause disordered micro-environment and decreased repair ability of local lung tissues, thus giving rise to the damage of lung tissues.

Theory of free radical oxidative damage: $\mathrm{PM}_{2.5}$ may bring about the increase of reactive oxygen species (ROS) in human body, with the potential routines including: $i$ ) The polycyclic aromatic hydrocarbon organic substances and metals in $\mathrm{PM}_{2.5}$. can produce oxygen free radicals; ii) The function of phagocytes in swallowing PM can consume large amount of oxygen, thus triggering abundant oxygen free radicals; iii) The damage and disintegration of phagocytes can also release abundant oxygen free radicals. This theory believes that the oxidative stress is one of the important mechanisms of deoxyribose nucleic acid (DNA) damage induced by PM (Kaur et al., 2013; Rizzo et al., 2014; Traversi et al., 2014).

Theory of macrophage injury: Lung phagocytes are distributed widely on the surfaces of bronchial alveoli, which can form a barrier against the external environment so as to reach its aim of protecting human body via swallowing the inhalable PM and pathogenic microorganisms. Meanwhile, they are one of the critical factors in maintaining the aseptic environment in lung because they can participate in the immunoregulatory process through playing the antigen presenting effect so as to activate the innate immunity. Lundborg et al (Lundborg et al., 2006) discovered that with the increase of carbon black PM dosage, the swallowing and adsorbing abilities of phagocytes decreased markedly in human body, indicating that PM could decrease the protective function of phagocytes by reducing their swallowing ability.

Difference analysis of $\mathrm{SO}_{2}$ concentrations on the number of visiting patients in Department of Respiratory

$\mathrm{SO}_{2}$, as one of the important air pollutants, is correlated with the gas emissions of motor vehicles. As a watersoluble stimulating gas, $\mathrm{SO}_{2}$ can be dissolved into the watery mucus of upper respiratory tract and bronchial mucous, which then is turned into sulfite or bisulfate and absorbed into blood. Then, it will rapidly spread to the whole body, stimulate the smooth muscle of respiratory tract, contract trachea and bronchus and increase the airway resistance and secretions. People who are exposed in high-concentration $\mathrm{SO}_{2}$ will have symptoms of wheeze and short breath, etc.

Epidemiological survey discovered that $\mathrm{SO}_{2}$ had high relevance with infantile asthma (Jassal, 2014). $\mathrm{SO}_{2}$ can induce acute aggravation of chronic lung diseases, which is more significant in patients with COPD. A study report pointed out that the hospitalization rate of COPD patients with acute aggravation could decrease $6 \%$ with the $\mathrm{SO}_{2}$ concentration decreased every $50 \mathrm{ug} / \mathrm{m}^{3}$ (Wagner et al., 2006). A research on the relationship between the air pollution and hospital treatment rate in Brisbane of Australia suggested that patients with respiratory decreased $8 \%$ with the $\mathrm{SO}_{2}$ concentration increased every 1 unit (Petroeschevsky et al., 2001). This study also found that $\mathrm{SO}_{2}$ concentration was in close association with the number of hospitalized patients with bronchial asthma, bronchitis, upper respiratory tract infection, COPD and pneumonia, and the higher the $\mathrm{SO}_{2}$ concentration, the larger the daily number of visiting patients, which was consistent with the results of studies at home and abroad.

An important pathogenesis of $\mathrm{SO}_{2}$ aggravating respiratory disease is the imbalance of oxidative stress and anti-oxidant response. Some pollutants, through the functions of ultraviolet, heat and water in air, may have photochemical reactions to produce oxidation products. For example, $\mathrm{O}_{3}$ and oxygenated compounds, through redox responses, can induce reactive oxidation products with activity and the oxidation products can aggravate the chronic inflammatory responses of trachea, leading to the aggravation of respiratory diseases (Bargagli et al., 2009).

In conclusion, the attack of respiratory diseases is in close connection with hazy weather. Therefore, the medical workers, especially the specialists in Department of Respiratory, should clearly recognize not only AQI values but also the weather changes so as to take appropriate measures for the diagnosis and treatment after predicating the symptoms, diagnosis and treatment of outpatients with respiratory diseases. In the United States, recognized standards (Laumbach et al., 2010) advocate that physicians should reduce the exposures and complications of patients in air pollution according to the daily AQI information, and guidance should be especially given to the infantile and elderly patients as well as those with bronchial asthma and chronic bronchitis. The physicians and patients could log in relevant websites to check the standard air quality parameter if they want to make out whether the local weather is standard or not so as to take corresponding measures. In China, the local air quality index can also be obtained from the website of Department of Environmental Protection, but hardly any people or physician is aware of checking the relevant information to help himself/herself or guide the patients, which should be improved and studied by all medical workers in Department of Respiratory.

\section{References}

Annesi-Maesano I, Moreau D, Caillaud D, et al (2007). Residential proximity fine particles related to allergic sensitisation and asthma in primary school children. Respir Med, 101, 1721-9.

Bargagli E, Olivieri C, Bennett D, et al (2009). Oxidative stress in the pathogenesis of diffuse lung diseases: a review. Respir Med, 103, 1245-56.

Brook RD, Rajagopalan S, Pope CA $3^{\text {rd }}$, et al (2010). Particulate matter air pollution and cardiovascular disease: An update to the scientific statement from the American heart association. 
Circulation, 121, 2331-78.

Brauer M1, Amann M, Burnett RT, et al (2012). Exposure assessment for estimation of the global burden of disease attributable to outdoor air pollution. Environ Sci Technol, 46, 652-60.

Deng X, Zhang F, Rui W, et al (2013). $\mathrm{PM}_{2.5}$-induced oxidative stress triggers autophagy in human lung epithelial A549 cells. Toxicol In Vitro, 27, 1762-70.

Deng X, Rui W, Zhang F, et al (2013). PM $_{2.5}$ induces Nrf2mediated defense mechanisms against oxidative stress by activating PIK3/AKT signaling pathway in human lung alveolar epithelial A549 cells. Cell Biol Toxicol, 29, 143-57.

Denholm R, Schüz J, Straif K, et al (2014). Is previous respiratory disease a risk factor for lung cancer? Am J Respir Crit Care Med, 190, 549-59.

Guo LJ, Zhao A, Chen RJ, et al (2014). Association between Ambient Air Pollution and Outpatient Visits for Acute Bronchitis in a Chinese City. Biomed Environ Sci, 27, 833-40.

Jassal MS (2014). Pediatric asthma and ambient pollutant levels in industrializing nations. Int Health, [Epub ahead of print].

Katanoda K, Sobue T, Satoh H, et al (2011). An association between long-term exposure to ambient air pollution and mortality from lung cancer and respiratory diseases in Japan. J Epidemiol, 21, 132-43.

Kaur S, Gill MS, Gupta K, et al (2013). Effect of occupation on lipid peroxidation and antioxidant status in coal-fired thermal plant workers. Int J Appl Basic Med Res, 3, 93-7.

Lippmann M, Gordon T, Chen LC (2005). Effects of subchronic exposures to concentrated ambient particles in mice. IX. Integral assessment and human health implications of subchronic exposures of mice to CAPs. Inhal Toxicol, 17, 255-61.

Lundborg M, Dahlén SE, Johard U, et al (2006). Aggregates of ultrafine particles impair phagocytosis of microorganisms by human alveolar macrophages. Environ Res, 100, 197-204.

Laumbach RJ (2010). Outdoor air pollutants and patient health. Am Fam Physician, 81, 175-80.

Lim SS, Vos T, Flaxman AD, et al (2012). A comparative risk assessment of burden of disease and injury attributable to 67 risk factors and risk factor clusters in 21 regions, 1990-2010: a systematic analysis for the Global Burden of Disease Study 2010. Lancet, 380, 2224-60.

McClellan RO (2012). Role of science and judgment in setting national ambient air quality standards: how low is low enough? Air Qual Atmos Health, 5, 243-58.

Meng X, Ma Y, Chen R, et al (2013). Size-fractionated particle number concentrations and daily mortality in a Chinese city. Environ Health Perspect, 121, 1174-8.

Oyana TJ, Rivers PA (2005). Geographic variations of childhood asthma hospitalization and outpatient visits and proximity to ambient pollution sources at a U.S.-Canada border crossing. Int J Health Geogr, 4, 14.

Petroeschevsky A, Simpson RW, Thalib L, et al (2001). Associations between outdoor air pollution and hospital admissions in Brisbane, Australia. Arch Environ Health, 56, 37-52.

Rouse RL, Murphy G, Boudreaux MJ, et al (2008). Soot nanoparticles promote biotransformation, oxidative stress, and inflammation in murine lungs. Am J Respir Cell Mol Biol, 39, 198-207.

Rückerl R, Hampel R, Breitner S, et al (2014). Associations between ambient air pollution and blood markers of inflammation and coagulation/fibrinolysis in susceptible populations. Environ Int, 70, 32-49.

Rizzo AM, Corsetto PA1, Farina F, et al (2014). Repeated intratracheal instillation of PM10 induces lipid reshaping in lung parenchyma and in extra-pulmonary tissues. PLoS One, 9, 106855.

Traversi D, Cervella P, Gilli G (2014). Evaluating the genotoxicity of urban PM2.5 using PCR-based methods in human lung cells and the Salmonella TA98 reverse test. Environ Sci Pollut Res Int, [Epub ahead of print].

Wagner U, Staats P, Fehmann HC, et al (2006). Analysis of airway secretions in a model of sulfur dioxide induced chronic obstructive pulmonary disease (COPD). J Occup Med Toxicol, $1,12$.

Wang KY, Chau TT (2013). An association between air pollution and daily outpatient visits for respiratory disease in a heavy industry area. PLoS One, 8, 75220. 